\title{
Effects of SCH23390 and spiperone administered into medial striatum and intermediate medial mesopallium on rewarding effects of morphine in day-old chicks
}

\author{
Xingu He ${ }^{\mathrm{a}, \mathrm{b}}$, Lin Xiao ${ }^{\mathrm{a}}$, Nan Sui ${ }^{\mathrm{a}, *}$ \\ a Key Lab of Mental Health, Institute of Psychology, Chinese Academy of Sciences Beijing, PR China \\ ${ }^{\mathrm{b}}$ Graduate School of the Chinese Academy of Sciences Beijing, PR China
}

\section{A R T I C L E I N F O}

\section{Article history:}

Received 25 May 2009

Received in revised form 23 September 2009

Accepted 14 October 2009

Available online 28 October 2009

\section{Keywords:}

Morphine

Conditioned place preference

The medial striatum

The intermediate medial mesopallium

Reward-related learning

Day-old chicks

\begin{abstract}
A B S T R A C T
In the avian forebrain, the medial striatum and the intermediate medial mesopallium are thought to be important structures for associative learning in chicks, where the role of dopaminergic systems in learning processes has been verified in various behavioral paradigms, such as one-trial passive avoidance learning. However, it is not yet clear whether the dopaminergic system of these regions is responsible for associative learning underlying cueelicited drug reward. In this study, a 6-day conditioning schedule in day-old chicks with i.p. morphine ( $2 \mathrm{mg} / \mathrm{kg})$ was used to compare the effects of intracerebrally injected dopamine $\mathrm{D}_{1}$ receptor antagonist, SCH23390, and $\mathrm{D}_{2}$ antagonist, spiperone. The antagonists were injected bilaterally ( $3 \mu \mathrm{g} / \mathrm{site})$ into either the medial striatum or the intermediate medial mesopallium, and tests were conducted on morphine-induced conditioned place preference or locomotor activity. The acquisition of place preference was significantly inhibited by SCH23390 in either the medial striatum or the intermediate medial mesopallium, but not by spiperone. However, in the medial striatum, but not in the intermediate medial mesopallium, the locomotor activity was blocked by both SCH23390 and spiperone. These data suggest that the medial striatum and the intermediate medial mesopallium in birds are differentially involved in the rewarding effects of morphine, and similarly to mammals, the dopamine $\mathrm{D}_{1}$ system may play an important role in the development of opiate reward.
\end{abstract}

Crown Copyright @ 2009 Published by Elsevier B.V. All rights reserved.

\section{Introduction}

It is well known that learning and memory have an important impact on morphine dependence and tolerance (Li et al., 2008; Zhai et al., 2008). An increasing body of behavioral literature shows that dopamine modulates learning and memory-related processes across a number of species and learning paradigms (Floresco and Phillips, 2001; Herold et al., 2008; Zarrindast et al., 2008). Dopamine can bind to two distinct receptors that are dichotomized into $D_{1}$-like $\left(D_{1}\right.$ and $\left.D_{5}\right)$ and $D_{2}$-like subfamilies $\left(D_{2}, D_{3}\right.$ and $\left.D_{4}\right)$. In the avian forebrain, the medial striatum and the intermediate medial mesopallium are crucial regions for learning and memory, where dopamine receptors $\left(D_{1}\right.$ and $\left.D_{2}\right)$ have been widely studied, especially in chicks (Csillag, 1999; Durstewitz et al., 1999).

Conditioned place preference is one of the more popular models for investigating the rewarding properties of drugs (Carr et al., 1989). On the other hand, it is a learning paradigm in which stimuli associated

\footnotetext{
* Corresponding author. Key Lab of Mental Health, Institute of Psychology, Chinese Academy of Sciences, PO Box 1603, 4A Datun Road, Chaoyang District, 100101, Beijing PR China. Tel.: +8610 64857369; fax: +86 1064872070 .

E-mail address: suin@psych.ac.cn (N. Sui).
}

with rewarding effects elicit approach behavior. Thus there may exist a certain correlation between drug reward and some kinds of learning and memory (Xu et al., 2001). Chicks of precocial birds have been often used as models of associative learning (Matsushima et al., 2003). Unlike the rodents with a relatively poor visual capacity, the chicks have highly evolved visual system which has been successfully utilized in establishing visually based conditioned place preference (Hughes et al., 1995). This may offer some advantages in modeling conditioned drug effects that are obtained when visual drug-associated stimuli are presented to humans in a controlled laboratory setting (Bardo and Bevins, 2000). Moreover, although the gross structure of avian and mammalian brains is radically different, there is evidence that there are connectional similarities in the brains of these two taxa which may explain their similar behavior and cognition (Emery, 2006). So, it may serve as excellent model system to investigate the effects and mechanisms of drugs of abuse. It is well known that dopaminergic $\mathrm{D}_{1}$ receptors play a particularly active role in the kind of reward-related learning that is implicated in the acquisition of morphine-induced conditioned place preference (Beninger and Miller, 1998; Rezayof et al., 2003; Sigala et al., 1997). In chick brain, the medial striatum is known to be important for the reinforcement of behavior and the anticipation of reward proximity (Balint et al., 2004; Izawa et al., 2002; Izawa et al., 2003; Yanagihara 
et al., 2001). Evidence also implicates the intermediate medial mesopallium in such phenomena, because lesions in this structure disrupt stimulus-reward associations and prevent chicks from demonstrating any preference for the reinforcing object (Awaya and Watanabe, 2003; Johnson and Horn, 1986).

In light of this information, we postulate that dopamine systems in the medial striatum and/or the intermediate medial mesopallium of chick forebrain may be important for the rewarding effects of morphine. The present study investigated morphine reward with the conditioned place preference paradigm in day-old chicks treated with specific antagonists of dopamine $\mathrm{D}_{1}$ or $\mathrm{D}_{2}$ receptors, SCH23390 $(\mathrm{R}(+)$-7-chloro-8-hydroxyl-3methyl-1-phenyl-2,3,4,5-tetrahydro-1H-3-benzazepine hydrochloride) or spiperone (8-[3-(p-Fluorobenzoyl)propyl]-1-phenyl-1,3,8-triazaspiro [4.5]decan-4-one), respectively, microinjected into the medial striatum and the intermediate medial mesopallium.

\section{Materials and Methods}

\subsection{Animal and housing}

Day-old male "Beijing white 939" chicks, weighing $40 \pm 5$ g, were commercially obtained from Beijing Brood Chick Company. All the chicks were housed in a colony room on an artificial light-dark cycle (lights on from 7 a.m. to 7 p.m.) with constant temperature $\left(28-30{ }^{\circ} \mathrm{C}\right.$ ) and humidity (55-65\%), and were allowed free access to food and water inside stainless metal mesh cages $(25 \mathrm{~cm} \times 22.5 \mathrm{~cm} \times 30 \mathrm{~cm}$; ten chicks per cage). All were adapted to laboratory conditions for at least 1 week before experiment. Each chick was used only once. The experimental protocol and procedure were carried out in accordance with the requirements of the National Institutes of Health Guide for Care and Use of Laboratory Animal (Publication No. 85-23, revised 1985).

\subsection{Apparatus}

Place conditioning was conducted in four identical black Perspex boxes, measuring $60 \mathrm{~cm} \times 30 \mathrm{~cm} \times 30 \mathrm{~cm}(1 \times w \times h)$. Each box was divided into two conditioning chambers of the same size by insertion of a vertical black Perspex divider. The two conditioning chambers had distinct floor colors: one green, the other red. During the conditioning phase, the divider was inserted to restrict the chick to the designed conditioning environment. A video camera was suspended from the ceiling to record the animal loci in the chambers simultaneously, and data were collected automatically. During conditioning and testing, the room was maintained at $28-30{ }^{\circ} \mathrm{C}$ and illuminated by four $60 \mathrm{~W}$ light bulbs hanging from the ceiling. All experiments were carried out between 8 a.m. and 4 p.m., in the light phase of the cycle.

\subsection{Drug preparation and i.c. administration}

The drugs used in the present experiment were morphine hydrochloride (Qinghai Pharmacological Co. Ltd, China), SCH23390 and spiperone (Sigma chemical Co, USA). Morphine was dissolved in $0.9 \%$ sterile saline; at a concentration of $1.0 \mathrm{mg} / \mathrm{ml}$ and injected intraperitoneally at a volume of $2 \mathrm{ml} / \mathrm{kg}$ body weight. SCH23390 and spiperone were dissolved in artificial CSF (aCSF) at a concentration of $3 \mu \mathrm{g} / \mu \mathrm{l}$ and given i.c. in a volume of $1 \mu \mathrm{l} /$ site. Because dopamine antagonists, and SCH23390 particularly, can induce sedation and motor impairments at higher doses (Lublin et al., 1993; Motles et al., 1993), we gave both drugs at $3 \mu \mathrm{g} / \mu \mathrm{l}$, in a dose previously found to block behavioral sensitization by i.c. apomorphine without causing motor or motivational defects (Acerbo and Delius, 2004). All drugs were dissolved just before the experiment. Control animals received saline.

Intracerebral injections were made with Hamilton micro-syringes as described previously (Kabai et al., 2004). Head holders were adjusted to direct injections into the medial striatum or the intermediate medial mesopallium. Injection sites were examined in a representative series of chicks with pontamine sky blue and found to cluster closely over the intended locations before launching the main experiments, at the stereotaxic coordinates for the medial striatum A $10.6 \mathrm{~mm}, \mathrm{~L} 1.2 \mathrm{~mm}$, D $3.2 \mathrm{~mm}$ and for the intermediate medial mesopallium $7.8 \mathrm{~mm}$, $1.0 \mathrm{~mm}$ and $7.5 \mathrm{~mm}$ from the Kuenzel and Masson (1988) chick brain atlas. SCH23390 or spiperone in 3- $\mu$ g doses ( $1 \mu$ l volume delivered over $1 \mathrm{~min}$ ) were delivered into both right and left hemispheres $15 \mathrm{~min}$ before the injection of morphine (three sessions) (Fig. 1). The chicks were given a further $15 \mathrm{~min}$ habituation period before conditioning sessions started.

\subsection{Behavioral testing}

The conditioned place preference paradigm consisted of a consecutive 8-day schedule with three distinct phases: pre-conditioning, conditioning and testing.

\subsubsection{Pre-conditioning}

On Day 1, all chicks were placed in the middle of the conditioning boxes with partitions removed and were allowed access to the entire apparatus for the next $15 \mathrm{~min}$. The time spent in each chamber was recorded to assess any unconditioned preference. Our preliminary experiment indicated that none of the subjects showed an unconditioned preference for either chamber. Considering that chicks could differentiate between the two chamber colors (Rosenzweig, 1990),
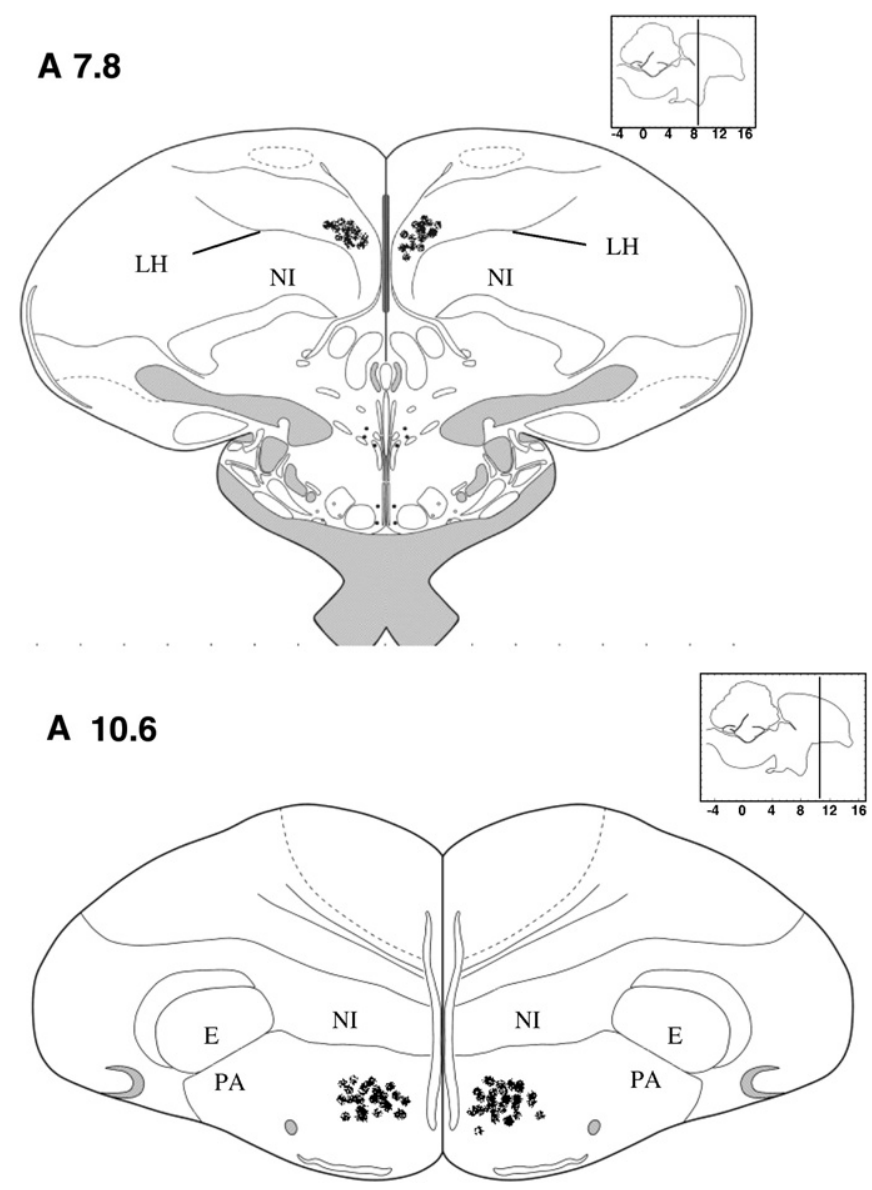

Fig. 1. Injection locations for the two sites are described in the text. For simplicity, the sites for both the medial striatum and the intermediate medial mesopallium are respectively mapped onto 10.6 - and $7.8-\mathrm{mm}$ anterior bilateral-side brain section drawings (Kuenzel and Masson, 1988), and the actual site locations spread between $0.5 \mathrm{~mm}$ more posterior and $0.5 \mathrm{~mm}$ more anterior. $\mathrm{E}=$ ectostriatum; $\mathrm{PA}=$ paleostriatum augmentatum; $\mathrm{NI}=$ neostriatum intermedium; $\mathrm{LH}=$ lamina hyperstriatica. 
during conditioning sessions, randomly, half of the chicks per group received morphine injection prior to placement in the green side and the others had morphine paired on the red side. All control chicks received saline injections on both sides.

\subsubsection{Conditioning}

Place conditioning phase started 1 day after pre-conditioning. Chicks were injected i.p. with saline or morphine $(2 \mathrm{mg} / \mathrm{kg}$ ) on alternate days and immediately placed in the saline- or morphine-assigned chamber for $45 \mathrm{~min}$. This dose of morphine was chosen after a pilot study showed it to be most effective in inducing CPP, in line with previous studies (Bronson et al., 1996). The chicks received only one conditioning session per day, in order to reduce the influence of possible morphine withdrawal effects when drug was absent (Cicero et al., 1997; Tzschentke and Schmidt, 1998). Conditioning was conducted over a 6-day period, counterbalanced between saline and morphine for a total of three saline pairings and three morphine pairings.

\subsubsection{Testing}

Tests of conditioned place preference were conducted 1 day after the last conditioning trial. The tests were similar to the pre-conditioning phase. Subjects were placed in the middle of the box with partitions removed and allowed free access to the entire apparatus for $15 \mathrm{~min}$. No injections were given on the day of the preference test. The amount of time spent in each chamber was recorded.

\subsection{Locomotor testing}

Based on established methods (Belzung and Barreau, 2000; Tzschentke and Schmidt, 1997), locomotor activity was measured during the testing phase, in a morphine-free state. Locomotion was tracked as horizontal distance expressed as pixel (2 pixels are equal to $1 \mathrm{~cm}$ ) and recorded traveled every 5 min during a 15-min period in the drug-paired chamber.

\subsection{Statistical analysis}

Place preference was assessed by time ratio (TR), which was calculated as the (time in drug-paired chamber)/(time in drug-paired chamber + time in vehicle-paired chamber). The greater the TR, the more time that the subject spent in the drug-paired chamber after conditioning. Data were analyzed using a two-factor repeated-measures ANOVA with groups (e.g. aCSF-morphine, SCH23390, spiperone) as the between-subjects factor and test (pre-conditioning and testing) as the within-subjects factor. For locomotor data, group differences were tested by one-way analyses of variance (ANOVA) followed by Tukey Honestly Significant Difference (HSD) post-hoc test. The experimental data were expressed as mean \pm S.E.M. The level of statistical significance was set at $P<0.05$. Calculations were performed using the SPSS 10.0 statistical package.

\section{Results}

3.1. Morphine-induced place preference after bilateral injections of SCH23390 or spiperone in the medial striatum

Morphine alone induced a robust place preference, which was not reduced by spiperone but was abolished by SCH23390 (Fig. 2). ANOVA of these data revealed a significant interaction between Group and Test $[F(1,22)=7.942, P<0.05]$. After conditioning, the aCSF-morphine treated chicks demonstrated robust preference for the drug-paired chamber $[F(1,11)=19.320, P<0.001]$, compared with the saline-treated group. SCH23390 inhibited the acquisition of place preference induced by morphine $[F(1,21)=10.494, P<0.05]$; while spiperone did not $[F(1,22)=4.322, P>0.05]$.

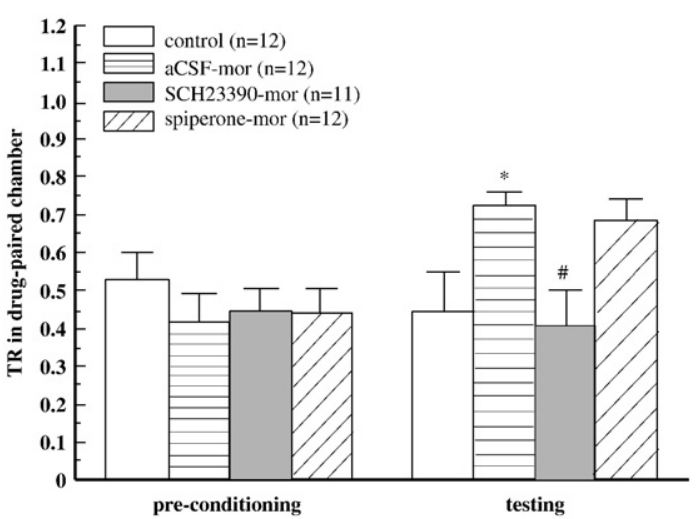

Fig. 2. Effects of bilateral the medial striatum injections of SCH23390 or spiperone ( $3 \mu \mathrm{g} /$ site) on the acquisition of morphine-induced place preference. Results are mean \pm S.E M. ${ }^{*}, P<0.05$, compared with control group; $\#, P<0.05$, compared with aCSF-morphine group. $\mathrm{TR}=$ time ratio.

3.2. Morphine-induced place preference after bilateral injections of SCH23390 or spiperone in the intermediate medial mesopallium

As shown in Fig. 3, again the aCSF-morphine group showed increased relative time in the drug-paired compartment compared with saline-treated controls, indicating a robust place preference $[F(1,18)=19.263, P<0.001]$, and injection of SCH23390 but not spiperone was able to block the acquisition of place preference induced by morphine $[F(1,16)=9.960, P<0.05]$.

\subsection{Psychostimulant effects of bilateral injections of SCH23390 or spiperone in the medial striatum}

Fig. 4 shows locomotor activity recorded during the testing phase after bilateral injection of $\mathrm{SCH} 23390$ or spiperone in the medial striatum during conditioning phase. One-way ANOVA showed that the four groups differed in locomotor activity not only in the first $5 \min [F(3,43)=20.16, P<0.0001]$ but also in the second $5 \min [F$ $(3,43)=11.19, P<0.0001]$ of a 15 -min period. Post-hoc analysis indicated that chicks treated with aCSF-morphine significantly increased their locomotion in the drug-paired chamber $(P<0.01)$ during both the 5 -min periods, compared with saline controls. Furthermore, intra- the medial striatum injection of $\mathrm{SCH} 23390$ or spiperone, during the conditioning phase, had obviously decreased

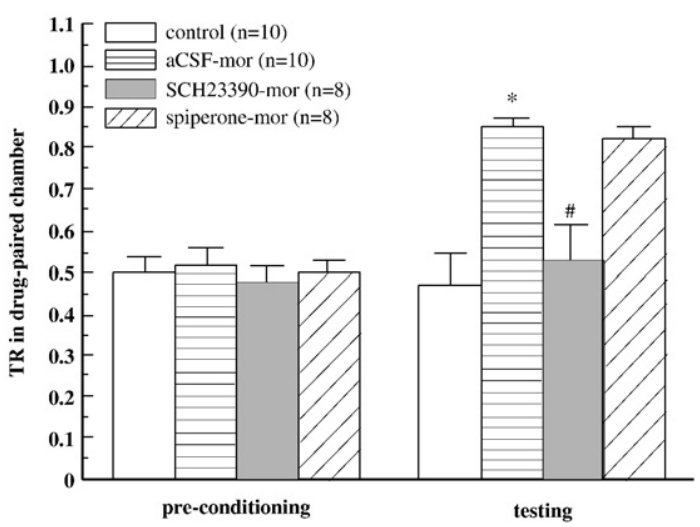

Fig. 3. Effects of bilateral the intermediate medial mesopallium injections of SCH23390 or spiperone $(3 \mu \mathrm{g} / \mathrm{site})$ on the acquisition of morphine-induced place preference. Results are mean \pm S.E.M. * $P<0.05$ versus control group; \#, $P<0.05$, versus aCSFmorphine group. $\mathrm{TR}=$ time ratio. 


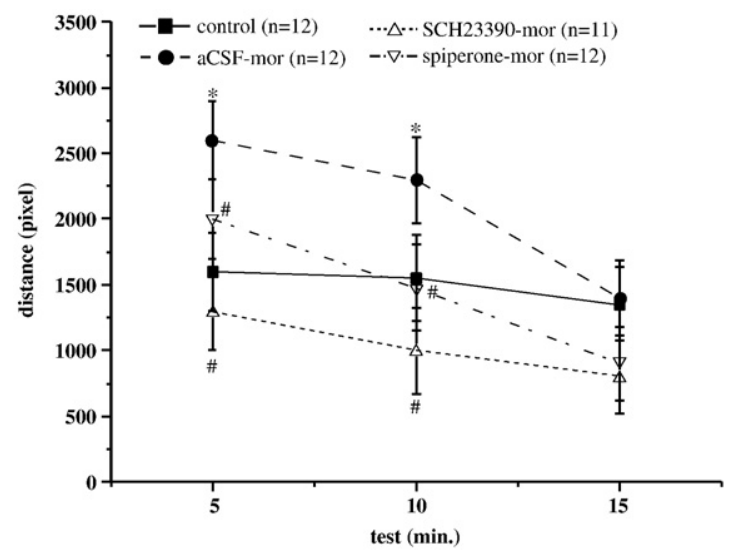

Fig. 4. Psychostimulant effects of bilateral injections of SCH23390 or spiperone ( $3 \mu \mathrm{g} /$ site) in the medial striatum. Locomotor activity for all groups was tested $24 \mathrm{~h}$ after the last conditioning session. Results are mean \pm S.E.M. * $P<0.01$, versus control group; \#, $P<0.01$, versus aCSF-morphine group.

locomotor activity during both first and second 5-min periods of the testing phase $(P<0.01)$, compared with aCSF-morphine groups. In contrast, there was no significant change in locomotor activity among the groups during any period of the testing phase with respect to the similar treatment in the intermediate medial mesopallium (data not shown).

\section{Discussion}

The present findings show for the first time that the medial striatum and the intermediate medial mesopallium, two key forebrain regions, are both involved in mediating the rewarding effects of morphine in chicks. This outcome implies that, as in mammals, opiate-induced conditioned place preference in chicks depends on the activation of dopamine-related brain areas. Our results demonstrated that morphine injections, $2 \mathrm{mg} / \mathrm{kg}$, i.p., induced robust conditioned preference for a morphine-associated compartment, consistent with previous findings in chicks (Bronson et al., 1996). Hence the present conditioning procedure should be suitable for further investigation of morphine's rewarding effects.

The role of the mesolimbic dopaminergic system in opioid reward is well documented in mammals (Spanagel and Weiss, 1999). The present work may be the first to test intra- the medial striatum administration of the $\mathrm{D}_{1}$ receptor antagonist, $\mathrm{SCH} 23390$, for effects on acquisition of morphine-induced place preference in the chick. Our results (Fig. 2) show that bilateral microinjections of SCH23390, when coupled with morphine in conditioning sessions, prevented the induction of preference for the morphine-paired chamber. The avian medial striatum (formerly termed lobus parolfactorius), is equivalent to the mammalian caudate-putamen. The medial striatum is known to be important for associative learning in the chick (Durstewitz et al., 1999; Matsushima et al., 2003), and the roles of dopamine $D_{1}$ receptors in such processes have been demonstrated (Kabai et al., 2004; Matsushima et al., 2001; Sherry et al., 2005). For example, autoradiographic studies have shown that $D_{1}$ receptors in the medial striatum are upregulated within 30 min of avoidance training (Stewart et al., 1996). Similarly, Kabai et al. (2004) reported that $\mathrm{SCH} 23390$ injected into the medial striatum before training would impair performance in tests conducted $30 \mathrm{~min}$ after training in a passive avoidance task. Some research strongly suggests that learning and memory are integral to opiate addiction (Li et al., 2008; Zhai et al., 2008). Indeed, it has been demonstrated that an intact signal at dopamine $D_{1}$ receptors is critical for the acquisition of responding for conditioned reward (Sutton and Beninger, 1999). These findings are fully consistent with pharmaco-behavioral studies on mammals showing that the acquisition of morphine-induced place preference can be suppressed by $D_{1}$ receptor antagonists (Fenu et al., 2006; Rezayof et al., 2003; Zarrindast et al., 2006). In light of this knowledge, it is reasonable to suggest that $D_{1}$ receptors in the medial striatum are implicated in the mediation of motivational effect of morphine. Moreover, while conditioned place preference paradigm has also been used to assess rewardrelated learning as a model of learning (Aujla and Beninger, 2003), it seems possible that SCH23390 may block learning of the association between morphine and the contextual stimulus. In support of our hypothesis, an increasing body of electrophysiological evidence provides some clues to how SCH23390 may be involved in synaptic plasticity that underlies reward-related learning (Abe et al., 2009; Centonze et al., 2001; Gurden et al., 2000; Schotanus and Chergui, 2008; Zhang et al., 2009). In addition, no claims could be made concerning state-dependent learning in the present study, which can be evaluated in test session conducted following injection of morphine or morphine plus SCH23390. However, it is noteworthy that the young chick is immature in its behavior, neuroanatomy and neurochemistry after all. It is possible that, although it is capable of learning and of other behaviors that resemble those of adult mammals, the underlying processes may differ from those that are obtained in adult mammals (Rose, 2000). Accordingly, although the chick model shows the similar responses to morphine as mammals in the current study, the comparison between avian and mammalian species obviously has lower stringency, so that more pharmacological experiments, studying the neural bases of reward-related learning in avian species, are necessary to improve our understanding of addiction learning among amniotes.

Our finding that the acquisition of morphine-induced place preference was also blocked by delivery of SCH23390 into the intermediate medial mesopallium is quite novel (Fig. 3). The intermediate medial mesopallium (previously termed the "intermediate medial hyperstriatum ventral") corresponds to portions of the mammalian association cortex, possibly the prefrontal and cingulate areas, and may function as a locus for collating signals from multimodal sensory inputs (Durstewitz et al., 1999). In passive avoidance learning, for example, the intermediate medial mesopallium may mediate associations between a visual image (e.g., a colored bead) and other features (e.g., bitter taste) during acquisition (Csillag, 1999). On the basis of these observations, we judged that the site was a plausible mediator for the acquisition of place preference induced by morphine. Present results support this hypothesis by indicating that a blockade of dopamine $D_{1}$ receptors in the intermediate medial mesopallium disrupted a learned association between contextual stimulus and morphine reward and in turn attenuated morphine-induced place preference. Further support comes from findings that dopaminergic $\mathrm{D}_{1}$ agonists do not interfere with the early phase of passive avoidance learning in day-old chicks (Hale and Crowe, 2002). Both the negative and the positive effects suggest that activation of $D_{1}$ receptors is associated with afferent dopaminergic reward or aversion signals, and this association may determine whether memory is developed for a given experiential pairing, as with image and taste (Kabai et al., 2004).

It should be mentioned, however, that $\mathrm{SCH} 23390$ by itself may elicit a conditioned place aversion (Manzanedo et al., 2001) or sedation (Hale and Crowe, 2003; Salmi and Ahlenius, 2000). Hence we cannot rule out the possibility that its interference with morphine-induced place preference reflects a place aversion that competes with morphineinduced place preference. Future studies are therefore needed to fully elucidate the effects of SCH23390 on behavioral functions in chicks. In contrast, our finding that the $\mathrm{D}_{2}$ antagonist spiperone in the same sites at a similar dose did not affect place preference induced by morphine is in agreement with previous indications showing that $D_{2}$-like receptors are less critical than $\mathrm{D}_{1}$-like receptors for reward-related learning (Sutton and Beninger, 1999). In this case also, however, there is room for further investigation since it has been reported that $D_{2}$ antagonists block morphine-induced place preference in some studies (Leone and Di Chiara, 1987; Suzuki and Misawa, 1995). 
Our study included basic locomotor observations intended to reveal any delayed effects of SCH23390 and spiperone on locomotor activity, $24 \mathrm{~h}$ after the last treatment, a time at which acute effects of the drugs on motor behavior should have ended. The results (Fig. 4) indicated that pretreatment with DA antagonists in the medial striatum either decreased or eliminated morphine-induced hyperactivity in the test session. Although the conditioned place preference paradigm is not an ideal model to study changes in locomotor activity after repeated drug treatments, it is worth noting that psychostimulant effects during conditioning sessions with morphine have been previously reported (Orsini et al., 2005). We are particularly interested to have observed that the negative psychomotor effects of dopamine antagonists in our tests occurred only in the medial striatum. This selectivity probably reflects the different neurochemical wiring in the striato-nigral and striato-tegmental pathways, which are remarkably similar in birds and mammals (Székely et al., 1994). In mammals, increased locomotor activity is considered to reflect increased dopaminergic transmission in the nigrostriatal and mesoaccumbens systems (Levens and Akins, 2001). Like these mammalian systems, and unlike the intermediate medial mesopallium, the avian medial striatum has reciprocal connections with midbrain dopaminergic nuclei (including the ventral tegmental area and the substantia nigra), which supply it with strong dopaminergic input (Csillag, 1999). Therefore, it is reasonable to infer that decreased locomotor activity by administration of DA receptor antagonists in the medial striatum reflects suppression of the nigrostriatal (tegmentostriatal) dopaminergic circuit. This, however, is another issue that merits further investigation.

Overall, the present results indicate that, in day-old male chicks, the medial striatum and the intermediate medial mesopallium of chick forebrain are differentially involved in the rewarding effects of morphine, and dopaminergic $D_{1}$ receptors play a crucial role in the acquisition of morphine-induced place preference, in accord with previous findings in mammals. This cross-species concordance means that the chick model, with its many advantages, may be useful in further studies of the neurochemistry and pharmacology of addiction learning.

\section{Acknowledgements}

We thank W.H. Gispen and anonymous referees for constructive comments which help improve the quality of the manuscript. This work was supported by Chinese Academy of Sciences Grants (KSCX2-SW204-02), National Natural Science Foundation Grants (30770719) and National Basic Research Program Grants (2009CB522002) to N. Sui. Prof. Brimijoin is thanked for his support during that visit, and his comments on an early and final version of this manuscript.

\section{References}

Abe, K., Fujimoto, T., Akaishi, T., Misawa, M., 2009. Basolateral amygdala D1- and D2dopaminergic system promotes the formation of long-term potentiation in the dentate gyrus of anesthetized rats. Prog. Neuro-psychopharmacol. Biol. Psychiatry 33, 552-556.

Acerbo, M.J. Delius, J.D. 2004. Behavioral sensitization to apomorphine in pigeons (Columba livia): blockade by the D1 dopamine antagonist SCH-23390. Behav. Neurosci. 118, 1080-1088

Aujla, H., Beninger, R.J., 2003. Intra-accumbens protein kinase C inhibitor NPC 15437 blocks amphetamine-produced conditioned place preference in rats. Behav. Brain Res. 147, 41-48.

Awaya, F., Watanabe, S., 2003. IMHV lesions caused deficits in conspecific discrimination in chicks but not in adult quail. NeuroReport 14, 1511-1514.

Balint, E., Kitka, T., Zachar, G., Adam, A., Hemmings, H.C., Csillag, A., 2004. Abundance and location of DARPP-32 in striato-tegmental circuits of domestic chicks. J. Chem. Neuroanat. 28, 27-36.

Bardo, M.T., Bevins, R.A., 2000. Conditioned place preference: what does it add to our preclinical understanding of drug reward? Psychopharmacology (Berlin) 153, 31-43.

Belzung, C., Barreau, S., 2000. Differences in drug-induced place conditioning between $\mathrm{BALB} / \mathrm{c}$ and $\mathrm{C57Bl} / 6$ mice. Pharmacol. Biochem. Behav. 65, 419-423.

Beninger, R.J., Miller, R., 1998. Dopamine D1-like receptors and reward-related incentive learning. Neurosci. Biobehav. Rev. 22, 335-345.

Bronson, M.E., Wages, T.D., Beddingfield, T., 1996. Morphine, MDMA, and Nexus produce a conditioned place preference in newly hatched chickens. Exp. Clin. Psychopharmacol. $4,352-362$.
Carr, G.D., Fibiger, H.C., Phillips, A.G., 1989. Conditioned place preference as a measure of drug reward. In: Leibman, J.M., Cooper, S.J. (Eds.), The Neuropharmacological Basis of Reward. Clarendon Press, Oxford, pp. 264-319.

Centonze, D., Picconi, B., Gubellini, P., Bernardi, G., Calabresi, P., 2001. Dopaminergic control of synaptic plasticity in the dorsal striatum. Eur. J. NeuroSci. 13, 1071-1077.

Cicero, T.J., Nock, B., Meyer, E.R., 1997. Sex-related differences in morphine's antinociceptive activity: relationship to serum and brain morphine concentrations. J. Pharmacol. Exp. Ther. 282, 939-944.

Csillag, A., 1999. Striato-telencephalic and striato-tegmental circuits: relevance to learning in domestic chicks. Behav. Brain Res. 98, 227-236.

Durstewitz, D., Kroner, S., Gunturkun, O., 1999. The dopaminergic innervation of the avian telencephalon. Prog. Neurobiol. 59, 161-195.

Emery, N.J., 2006. Cognitive ornithology :the evolution of avian intelligence. Philos. Trans. R. Soc. Lond., B Biol. Sci. 361, 23-43.

Fenu, S., Spina, L., Rivas, E. Longoni, R., Di Chiara, G. 2006. Morphine-conditioned singletrial place preference: role of nucleus accumbens shell dopamine receptors in acquisition, but not expression. Psychopharmacology 187, 143-153.

Floresco, S.B., Phillips, A.G., 2001. Delay-dependent modulation of memory retrieval by infusion of a dopamine D1 agonist into the rat medial prefrontal cortex. Behav. Neurosci. 115, 934-939.

Gurden, H., Takita, M., Jay, T.M., 2000. Essential role of D1 but not D2 receptors in the NMDA receptor-dependent long-term potentiation at hippocampal-prefrontal cortex synapses in vivo. J. Neurosci. 20, 1-5.

Hale, M.W., Crowe, S.F., 2002. The effects of selective dopamine agonists on a passive avoidance learning task in the day-old chick. Behav. Pharmacol. 13, 295-301.

Hale, M.W., Crowe, S.F., 2003. Facilitation and disruption of memory for the passive avoidance task in the day-old chick using dopamine D1 receptor compounds. Behav. Pharmacol. 14, 525-532.

Herold, C., Diekamp, B., Gunturkun, O., 2008. Stimulation of dopamine D1 receptors in the avian fronto-striatal system adjusts daily cognitive fluctuations. Behav. Brain Res. 194, 223-229.

Hughes, R.A., Baker, M.R., Retting, K.M., 1995. Cocaine-conditioned place preference in young precocial domestic fowl. Exp. Clin. Psychopharmacol. 3, 105-111.

Izawa, E.-I., Zachar, G., Aoki, N., Koga, K., Matsushima, T., 2002. Lesions of ventro-medial basal ganglia impair the reinforcement but not recall of memorized color discrimination in domestic chicks. Behav. Brain Res. 136, 405-414.

Izawa, E.I., Zachar, G., Yanagihara, S., Matsushima, T., 2003. Localized lesion of caudal part of lobus parolfactorius caused impulsive choice in the domestic chick: evolutionarily conserved function of ventral striatum. J. Neurosci. 23, 1894-1902.

Johnson, M.H., Horn, G., 1986. Dissociation of recognition memory and associative learning by a restricted lesion of the chick forebrain. Neuropsychologia 24, 329-340.

Kabai, P., Stewart, M.G., Tarcali, J., Csillag, A., 2004. Inhibiting effect of D1, but not D2 antagonist administered to the striatum on retention of passive avoidance in the chick. Neurobiol. Learn. Mem. 81, 155-158.

Kuenzel, W.J., Masson, M., 1988. A Stereotaxic Atlas of the Brain of the Chick (Gallus domesticus), eighth ed. Johns Hopkins University Press, Baltimore. PP. 50-64

Leone, P., Di Chiara, G., 1987. Blockade of D-1 receptors by SCH 23390 antagonizes morphineand amphetamine-induced place preference conditioning. Eur. J. Pharmacol. 135 251-254.

Levens, N., Akins, C.K., 2001. Cocaine induces conditioned place preference and increases locomotor activity in male Japanese quail. Pharmacol. Biochem. Behav. 68, 71-80.

Li, T., Yan, C.X., Hou, Y., Cao, W., Chen, T., Zhu, B.F., Li, S.B., 2008. Cue-elicited drug craving represses ERK activation in mice prefrontal association cortex. Neurosci. Lett. 448, 99-104.

Lublin, H., Gerlach, J., Peacock, L., 1993. Chronic treatment with the D1 receptor antagonist SCH 23390, and the D2 receptor antagonist, raclopride, in cebus monkeys withdrawn from previous haloperidol treatment. Extrapyramidal syndromes and dopaminergic supersensitivity. Psychopharmacology (Berlin) 112, 389-397.

Manzanedo, C., Aguilar, M.A., Rodriguez-Arias, M., Minarro, J., 2001. Effects of dopamine antagonists with different receptor blockade profiles on morphine-induced place preference in male mice. Behav. Brain Res. 121, 189-197.

Matsushima, T., Izawa, E.I., Yanagihara, S., 2001. D1-receptor dependent synaptic potentiation in the basal ganglia of quail chicks. NeuroReport 12, 2831-2837.

Matsushima, T., Izawa, E., Aoki, N., Yanagihara, S., 2003. The mind through chick eyes: memory, cognition and anticipation. Zool. Sci. 20, 395-408.

Motles, E., Gomez, A., Tetas, M., Gonzalez, M., 1993. Effects of SCH 23390 and sulpiride on the behaviors evoked by amphetamine and apomorphine in adult cats. Prog Neuro-psychopharmacol. Biol. Psychiatry 17, 1005-1022.

Orsini, C., Bonito-Oliva, A., Conversi, D., Cabib, S., 2005. Susceptibility to conditioned place preference induced by addictive drugs in mice of the C57BL/6 and DBA/2 inbred strains. Psychopharmacology (Berlin) 181, 327-336.

Rezayof, A., Zarrindast, M.R., Sahraei, H., Haeri-Rohani, A., 2003. Involvement of dopamine receptors of the dorsal hippocampus on the acquisition and expression of morphineinduced place preference in rats. J. Psychopharmacol. 17, 415-423.

Rose, S.P.R., 2000. God's organism? The chick as a model system for memory studies. Learn. Mem. 7, 1-17.

Rosenzweig, M.R., 1990. The chick as a model system for studying neural processes in learning and memory. NIDA Res. Monogr. 97, 1-21.

Salmi, P., Ahlenius, S., 2000. Sedative effects of the dopamine D1 receptor agonist A 68930 on rat open-field behavior. NeuroReport 11, 1269-1272.

Schotanus, S.M., Chergui, K., 2008. Dopamine D1 receptors and group I metabotropic glutamate receptors contribute to the induction of long-term potentiation in the nucleus accumbens. Neuropharmacology 54, 837-844.

Sherry, J.M., Hale, M.W., Crowe, S.F., 2005. The effects of the dopamine D1 receptor antagonist $\mathrm{SCH} 23390$ on memory reconsolidation following reminder-activated retrieval in day-old chicks. Neurobiol. Learn. Mem. 83, 104-112. 
Sigala, S., Missale, C., Spano, P., 1997. Opposite effects of dopamine D-2 and D-3 receptors on learning memory in the rat. Eur. J. Pharmacol. 336, 107-112.

Spanagel, R., Weiss, F., 1999. The dopamine hypothesis of reward: past and current status. Trends Neurosci. 22, 521-527.

Stewart, M.G., Kabai, P., Harrison, E., Steele, R.J., Kossut, M., Gierdalski, M., Csillag, A., 1996. The involvement of dopamine in the striatum in passive avoidance training in the chick. Neuroscience 70, 7-14.

Sutton, M.A., Beninger, R.J., 1999. Psychopharmacology of conditioned reward: evidence for a rewarding signal at D1-like dopamine receptors. Psychopharmacology (Berlin) 144, 95-110.

Suzuki, T., Misawa, M., 1995. Sertindole antagonizes morphine-, cocaine-, and methamphetamine-induced place preference in the rat. Life Sci. 57, 1277-1284.

Székely, A., Boxer, M., Stewart, M., Csillag, A., 1994. Connectivity of the lobus parolfactorius of the domestic chicken (Gallus domesticus): an anterograde and retrograde pathway tracing study. J. Comp. Neurol. 348, 374-393.

Tzschentke, T.M., Schmidt, W.J., 1997. Interactions of MK-801 and GYKI 52466 with morphine and amphetamine in place preference conditioning and behavioural sensitization. Behav. Brain Res. 84, 99-107.

Tzschentke, T.M., Schmidt, W.J., 1998. Blockade of morphine- and amphetamineinduced conditioned place preference in the rat by riluzole. Neurosci. Lett. 242, 114-116.
Xu, N., Wang, L., Wu, C., Pei, G., 2001. Spatial learning and morphine-rewarded place preference negatively correlates in mice. Pharmacol. Biochem. Behav. 68, 389-394.

Yanagihara, S., Izawa, E.I., Koga, K., Matsushima, T., 2001. Reward-related neuronal activities in basal ganglia of domestic chicks. NeuroReport 12, 1431-1435.

Zarrindast, M.R., Azami, B.N., Rostami, P., Rezayof, A., 2006. Repeated administration of dopaminergic agents in the nucleus accumbens and morphine-induced place preference. Behav. Brain Res. 169, 248-255.

Zarrindast, M.R. Hoghooghi, V., Rezayof, A 2008. Inhibition of morphine-induced amnesia in morphine-sensitized mice: involvement of dorsal hippocampal GABAergic receptors. Neuropharmacology 54, 569-576.

Zhai, H., Li, Y., Wang, X., Lu, L., 2008. Drug-induced alterations in the extracellular signalregulated kinase (ERK) signalling pathway: implications for reinforcement and reinstatement. Cell. Mol. Neurobiol. 28, 157-172.

Zhang, J.C., Lau, P.M., Bi, G.Q., 2009. Gain in sensitivity and loss in temporal contrast of STDP by dopaminergic modulation at hippocampal synapses. Proc. Natl. Acad. Sci. U. S. A. 106, 13028-13033. 